\title{
Towards a Heuristic Research Model Linking Early Socioeconomic Adversity and Youth Cumulative Disease Risk: An Integrative Review
}

\author{
K. A. S. Wickrama ${ }^{1}$ Catherine Walker O'Neal ${ }^{2}$ Christopher Holmes $^{3}$
}

Received: 7 February 2017 / Accepted: 13 April 2017 / Published online: 28 April 2017

(C) Springer International Publishing 2017

\begin{abstract}
This integrative review draws on previous empirical and theoretical work across multiple research traditions, including psychology, sociology, and neurology, to create a framework detailing pathways linking early socioeconomic adversity in childhood and adolescence to subsequent disease risk later in adolescence and young adulthood. A comprehensive search ultimately led to the socioeconomic adversity and disease risk model for youth, which is a heuristic research framework detailing four overarching pathways focused on early biological/genetic vulnerability, physiological responses (comprised of stress responses and hormonal activity), psychosocial resource trajectories, and behavioral and mental health trajectories as well as potential modifiers of these pathways. Other central constructs include brain development/neuroplasticity and adolescent life stressors. The heuristic research framework calls for an integrated perspective taking a longview over early life course to explain cumulative physical disease risk by combining knowledge from developmental, social, neurocognitive, and biological sciences.
\end{abstract}

Catherine Walker O'Neal

cwalker1@uga.edu

K. A. S. Wickrama

wickrama@uga.edu

Christopher Holmes

Holmes11@uga.edu

1 Department of Human Development and Family Science, The University of Georgia, 103 Family Science Center I, Athens, Georgia

2 Department of Human Development and Family Science, The University of Georgia, 107 Family Science Center II, Athens, Georgia

3 Center for Family Research, The University of Georgia, 217 Nichols Building, Athens, Georgia
Keywords Socioeconomic adversity $\cdot$ SES $\cdot$ Disease risk $\cdot$ Stress $\cdot$ Physical health

\section{Introduction}

Previous research has documented the persistent association between early socioeconomic adversity (i.e., in childhood or early adolescence) and subsequent physical disease risk in later adolescence and young adulthood (Costello et al. 2003; Wickrama et al. 2015b), which leads to health inequalities in adulthood (e.g., Center on Social Determinants of Health 2008; Cohen et al. 2010; Nurius et al. 2015; Seeman et al. 2010). Here, adolescence is conceptualized as 13-19 years, young adulthood is defined as $25-40$ years, and the transition from adolescence to young adulthood, or emerging adulthood, is conceptualized as 19-25 years of age. Previous empirical and theoretical work across several research traditions has identified different, but related, mediating and moderating mechanisms responsible for the connection between early socioeconomic adversity and physical health (e.g., physiological and behavioral processes as well as psychosocial resources and early biological vulnerability) (e.g., McEwen and Gianaros 2010; Miller and Cole 2012; Raposa et al. 2014). That is, the association between early socioeconomic adversity and physical health has been studied in various research domains: biological health, psychological health, and behavioral health and utilizing various lens from various perspectives: stress, resource, and resilience, to name a few. While these advanced studies have yielded a large body of research from which to draw, the lack of integration across disciplines is problematic for the development of a comprehensive understanding of how early socioeconomic adversity contributes to physical health risk. 
To this end, we believe that a review of these mechanisms resulting in testable models within an integrated framework is necessary to incorporate findings from multiple disciplines. This is particularly timely given that multidimensional datasets (e.g., data on genetics, biomarkers, and mental and physical health diagnoses) within multilevel, prospective longitudinal research designs are increasingly common. Consequently, the resulting socioeconomic adversity and disease risk (SADR) model serves as a heuristic organizing framework that can guide future research to advance multi-disciplinary research and interventions related to the early socioeconomic adversity-physical health connection. We label our SADR model as a heuristic organizing framework (where heuristic means to find or discover) because it was derived from our own exploration of existing research, both theoretical and empirical.

Our exploration and comprehension of the research was grounded in our understanding of the life course perspective and stress process theory (Elder et al. 2003; Pearlin et al. 2005). Particular life course concepts guiding the creation of our SADR model include a "long view" over the life course, the effects of cumulative influences, stress proliferation, path dependent and exposure dependent pathways, turning points in individuals' lives, and a focus on the timing and sequence of life events (Elder and Giele 2009; Willson et al. 2007). Here, we build on existing work that has integrated ecological and biopsychosocial approaches to understand health disparities and inequalities. Such work has increasingly emphasized that the study of health and health behavior in isolation from the broader social and environmental context and life course experiences is incomplete (e.g., Ganzel et al. 2010; Solar and Irwin 2010). For instance, Glass and McAtee (2006) proposed a model with both temporal and multilevel structural dimensions for the investigation of health outcomes. The temporal dimension takes into account life course from early life to later life (i.e., upstream to downstream). The multilevel dimension identifies nested hierarchies of structure (i.e., underwater to uphill) each with opportunities and constraints. We expect to strengthen such existing frameworks with the addition of more specific testable mechanisms.

While we do not provide a thorough review of the life course perspective here, we briefly summarize how some of these concepts are relevant to the work at hand. Our heuristic research framework takes a "long view" of the early life course beginning with early stressful life experiences associated with early socioeconomic adversity (or affluence), which proliferate over adolescence and the transition to adulthood as the accrual of sequentially-contingent stressful circumstances (or resources) (i.e., stress trajectories). Also, consistent with the notion of risk (or resource) accumulation and cumulative disadvantage (or advantage) from the life course perspective (Dannefer 2003), we consider disease risk development as a lifelong adaptive process (Braveman and Barclay 2009; Halfon and Hochstein 2002).

\section{The Current Study}

The aim of the current article is to utilize life course and stress process concepts to integrate previous research from multiple disciplines into an overarching and relatively comprehensive framework, which we termed the SADR model. While this broad view limits our ability to provide in-depth detailed discussion about responsible mechanisms, its strength is its presentation of a framework that can be utilized to derive testable models for future research exploring links from early socioeconomic adversity to subsequent physical disease risk. Figure 1 illustrates the SADR model with four pathways stemming from early socioeconomic adversity and leading to increased risk for various physical diseases in late adolescence and young adulthood. Table 1 provides examples of the various constructs contained within the larger heading titles shown in Fig. 1. The four pathways in Fig. 1, which are shown in colors other than white for emphasis, include early biological or genetic liabilities and vulnerabilities as well as three parallel pathways [i.e., physiological (stress response-hormonal), behavioral, and psychosocial resource pathways] or growth trajectories (e.g., Matthews and Gallo 2011; Wickrama et al. 2015b). The three parallel pathways represent not only the initial levels but also growth or development in these attributes over early life course. In Fig. 1, single-headed arrows depict uni-directional, additive influences whereas lines with arrows on each end depict bi-directional, often simultaneous, associations. Table 2 provides details of potential modifiers associated with these pathways.

\section{Method}

In the paragraphs that follow, rather than reviewing previous research in detail or discussing disease-specific mechanisms in detail, we provide an overall summary of key findings from existing empirical studies to support the proposed pathways and associations leading to increased physical disease risk as depicted in Fig. 1 moving from left to right. Although, the pathways in Fig. 1 imply sequential processes, it should be noted that some associations depicted in the figure may be simultaneous and bi-directional. The search strategy included a review of APA PsycNet, PubMed, PsycINFO, and Google Scholar databases. Emphasis was placed on articles since 2000; however, seminal and well-cited research prior to 2000 were also incorporated. Primary search terms included: socioeconomic adversity, socioeconomic status, socioeconomic disadvantage, early 


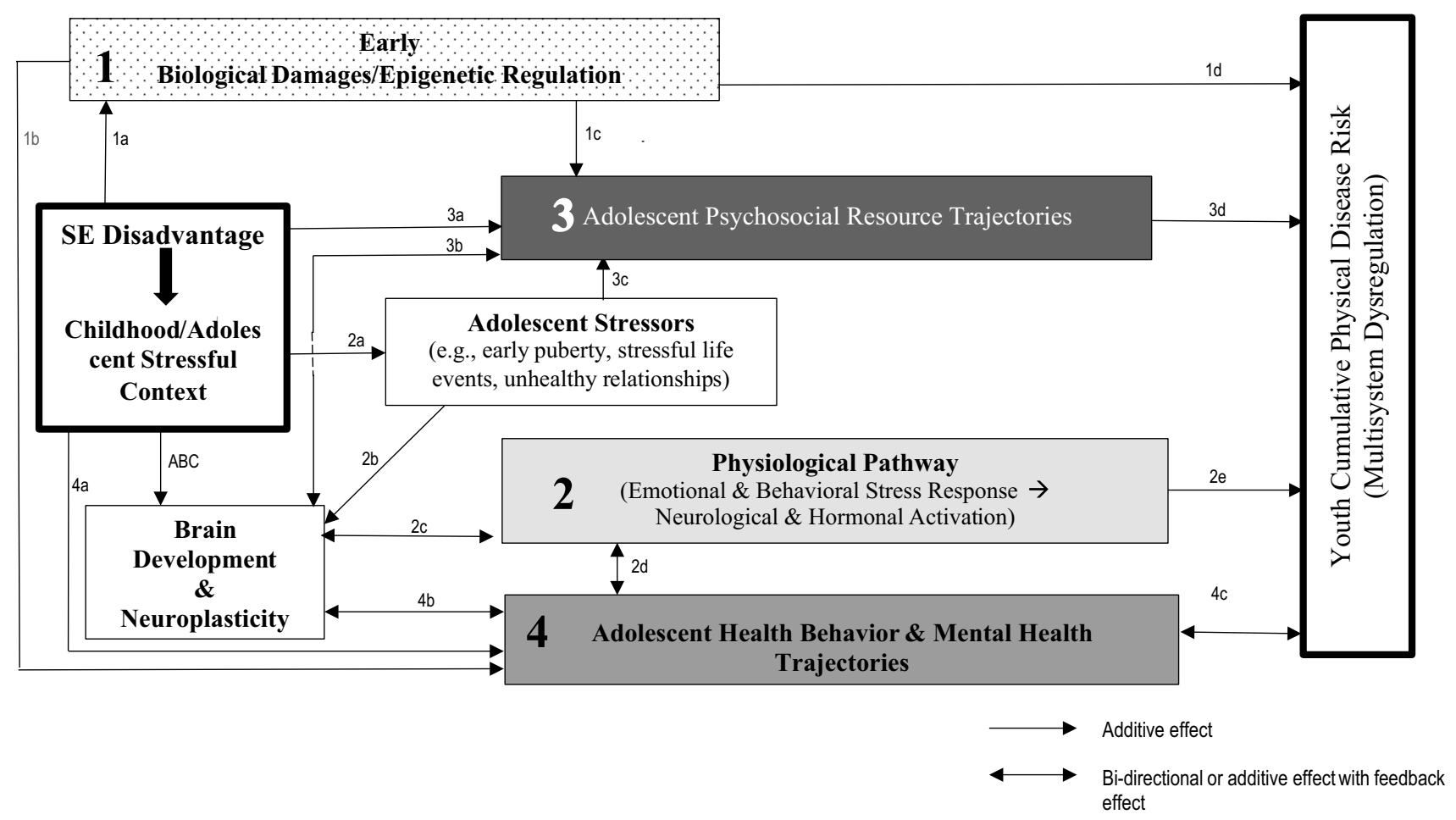

Fig. 1 The socioeconomic adversity and disease risk (SADR) model: an integrated research framework linking early socioeconomic adversity and adolescent/young adult cumulative disease risk. The four

vulnerability, adolescent stress, puberty, adolescent physical health, young adult physical health, metabolic syndrome, inflammation, blood pressure, health behaviors, and allostatic load. We then sought to include literature (1) published in the English language, (2) incorporating neurobiological research findings into traditional life course stress process models, and (3) focusing on the early life course (infancy through adolescence) or-where appropriate-applying findings from adult populations to early life course development. This search yielded an outline of the organizing framework presented here. As a second step, supplementary searches were performed to flesh out more specific empirical details for each mechanism and ensure the existence of sufficient evidence for the proposed pathway and associations. These supplementary searches relied on key terms from specific articles found in the initial search as well as an examination of citations made by these articles and articles that cited these articles.

\section{Early Socioeconomic Adversity: Socioeconomic Disadvantage and Stressful Life Contexts}

Early socioeconomic disadvantage creates a stressful life context for children and adolescents. Early socioeconomic disadvantage is characterized by low proposed pathways are shown in colors other than white for emphasis. Proposed effect modifications for the paths presented here are detailed in Table 2

socioeconomic status (SES) and often marked by family characteristics, such as low family income, low parental education, and parents' disrupted marital status, as well as by adverse community characteristics and racial/ethnic minority status (Conger et al. 2010; Evans and Kim 2010). Thus, the influence of early adversity on youth's physical health should be evaluated in the context of the broader social and physical environments in which youth live (Schreier and Chen 2013). Family socioeconomic disadvantage generates stressful life contexts characterized by disrupted family processes, including parents' marital conflicts, ineffective parenting (Conger et al. 2010; Repetti et al. 2002), parental negligence, rejection and abuse (Anda et al. 2006), lack of cognitive stimulation (Stack et al. 2015), stressful family events (Ge et al. 2001), and family economic pressure (Conger et al. 2000). Community socioeconomic disadvantage is reflected by a lack of physical and/or social resources, high residential instability, a high poverty rate, high crime rates, and a high percentage of single parent households; like family disadvantage, these community disadvantages also generate stressful, dangerous, and often threatening, environments for adolescents (i.e., "community stress", Ross and Mirowsky 2009). Furthermore, minority youth (including racial/ethnic minorities as well as other minorities such as LGBT youth) frequently 
Table 1 Important concepts comprising the SADR model illustrated in Fig. 1 (example constructs in parentheses)

\begin{tabular}{|c|c|c|}
\hline Early socioeconomic adversity & Psychosocial resource trajectories & Emotional and behavioral stress responses \\
\hline Parental education & Personality (positive affect) & Anxiety \\
\hline Family income & Intelligence (GPA) & Anger \\
\hline Parent occupation (work complexity, prestige) & Perceptions of self (self-esteem, self-efficacy) & Aggression \\
\hline $\begin{array}{l}\text { Parental Marital Status (previous marital } \\
\text { history) }\end{array}$ & $\begin{array}{l}\text { Psychological abilities (mastery, self control, } \\
\text { resistance to peers) }\end{array}$ & $\begin{array}{l}\text { Frustration } \\
\text { Impatience }\end{array}$ \\
\hline $\begin{array}{l}\text { Community adversity (poverty rate, unem- } \\
\text { ployment) }\end{array}$ & $\begin{array}{l}\text { Altruism } \\
\text { Spirituality }\end{array}$ & Helplessness \\
\hline $\begin{array}{l}\text { Race/ethnic minority status (immigration } \\
\text { status) }\end{array}$ & $\begin{array}{l}\text { Social support (from adults, teacher, peers) } \\
\text { Acculturation }\end{array}$ & \\
\hline $\begin{array}{l}\text { Stressful socioeconomic contexts } \\
\text { Ineffective parenting (negligence, rejection, } \\
\text { and abuse) } \\
\text { Lack of cognitive stimulation } \\
\text { Family stressful events (parental divorce or } \\
\text { conflict, deaths, illnesses) } \\
\text { Family economic pressure } \\
\text { Community stress (threats, violence) } \\
\text { Minority stress } \\
\text { Discrimination }\end{array}$ & $\begin{array}{l}\text { Adolescent stressors } \\
\text { Synchronization and timing of puberty } \\
\text { Stressful life events (SLEs) } \\
\text { Relationship difficulties (quality, satisfaction, } \\
\text { conflict) } \\
\text { Life transition patterns (timing and sequence } \\
\text { of life events such as: graduation, marriage, } \\
\text { pregnancy, parenthood) } \\
\text { Parent-child differential acculturation }\end{array}$ & $\begin{array}{l}\text { Physiological pathway (hormonal activity) } \\
\text { Neuroendocrine Systems } \\
\text { HPA Axis \& SAM axis activation } \\
\text { Secondary Systems } \\
\text { Metabolic, cardiovascular, and immune system } \\
\text { dysregulation }\end{array}$ \\
\hline $\begin{array}{l}\text { Brain development and neuroplasticity } \\
\text { Structure } \\
\text { Prefrontal cortex } \\
\text { Amygdala } \\
\text { Hippocampus } \\
\text { Functioning } \\
\text { Cognitive processing } \\
\text { Emotional regulation }\end{array}$ & $\begin{array}{l}\text { Health behavior and mental health trajec- } \\
\text { tories } \\
\text { Substance use (tobacco, alcohol, illegal drugs) } \\
\text { Sexual behavior (onset, use of protection, } \\
\text { number of partners) } \\
\text { Physical inactivity (screen time) } \\
\text { BMI } \\
\text { Eating Behavior (fat and sugar content, fruits } \\
\text { and vegetables) } \\
\text { Behavioral withdrawal } \\
\text { Depressive symptoms }\end{array}$ & $\begin{array}{l}\text { Accumulating disease risk } \\
\text { Domains of health risk } \\
\text { Psychological health Cognitive health } \\
\text { Behavioral health } \\
\text { Multisystem Dysregulation } \\
\text { Biomarker measures capturing allostatic load } \\
\text { (BMI, BP, HR, A1c) }\end{array}$ \\
\hline $\begin{array}{l}\text { Early biological/genetic vulnerability } \\
\text { Birthweight } \\
\text { Pre-term birth disability } \\
\text { Illness } \\
\text { Impaired/delayed growth } \\
\text { Biological programming } \\
\text { Genetic expression }\end{array}$ & & \\
\hline
\end{tabular}

encounter "minority stress" including prejudice and discrimination (Brody et al. 2006; Meyer 1995; Noh et al. 1999; Noh and Kaspar 2003).

Most previous developmental studies have examined these different dimensions of youth stressful life experiences stemming from early socioeconomic adversity one at a time (that is, in isolation from one another). For our purpose, however, we use the terms early socioeconomic adversity and early adversity when referring to both socioeconomic disadvantage and early stressful life contexts. Socioeconomic disadvantage components of early adversity include SES characteristics that are generally considered "structural," such as lack of parental education. Early stressful life contexts components of early adversity include the stressful experiences related to the structural characteristics of SES. An example of an early stressful life context is parental rejection. This conceptualization of early adversity is in line with the multiple risk exposure notion (Evans and Kim 2010), which posits that a cumulative measure of the risks associated with early socioeconomic adversity (both structural characteristics and stressful experiences) is a more powerful predictor of later outcomes compared to independent measures of single risk exposures because early risks co-vary. Furthermore, researchers have concluded that an additive formulation of these risk factors, rather than an interactive formulation, more adequately captures adolescents' exposure to cumulative developmental risks (Bauman et al. 2006). For example, a study utilizing both structural characteristics (i.e., parental occupation) and stressful experiences (i.e., childhood maltreatment and childhood social isolation), found these early socioeconomic adversities independently predicted abnormalities in stress-sensitive biological systems, including nervous, immune, and endocrine/metabolic systems, in young adulthood (Danese et al. 2009). While acknowledging the unique influences of individual structural adversities and different 
Table 2 Examples for potential modifiers of the associations depicted in Fig. 1

\begin{tabular}{|c|c|c|c|}
\hline \multicolumn{3}{|c|}{ Association } & \multirow[t]{2}{*}{ Example modifiers/resilience factors } \\
\hline Path \# & Exogenous Construct & Endogenous Construct & \\
\hline $2 \mathrm{a}$ & Early socioeconomic disadvantages/context & Adolescent stressors & $\begin{array}{l}\text { Psychological resources (e.g., personality, self-regu- } \\
\text { lation, impulse control, "John Henryism", "shift and } \\
\text { persist") } \\
\text { Social resources (e.g., social support, high quality } \\
\text { parenting) } \\
\text { Genetic polymorphisms }\end{array}$ \\
\hline $3 a$ & Early socioeconomic disadvantages/context & Psychosocial resources & $\begin{array}{l}\text { Early biological damages, genetic predisposition (e.g., } \\
\text { disability, impaired growth, genetic polymorphism) }\end{array}$ \\
\hline $4 \mathrm{a}$ & Early socioeconomic disadvantages/context & Health behavior and mental health & $\begin{array}{l}\text { Psychological resources (e.g., personality, self-regu- } \\
\text { lation, impulse control, "John Henryism", "shift and } \\
\text { persist") } \\
\text { Social resources (e.g., social support, effective parent- } \\
\text { ing, positive peer relations, adult role models) } \\
\text { Genetic polymorphisms }\end{array}$ \\
\hline $2 b, 2 c$ & Adolescent stressors & Physiological pathway & $\begin{array}{l}\text { Psychological resources (e.g., personality, self-regu- } \\
\text { lation, impulse control, "John Henryism", "shift and } \\
\text { persist") } \\
\text { Social resources (e.g., social support, effective parent- } \\
\text { ing, positive peer relations, adult role models) } \\
\text { Early biological damages } \\
\text { Early stressful life experiences ("stress potentiation") } \\
\text { (e.g., parental rejection, negligence, community } \\
\text { stress) }\end{array}$ \\
\hline $2 b, 4 b$ & Adolescent stressors & Health behavior and mental health & $\begin{array}{l}\text { Psychological resources (e.g., self-regulation, accul- } \\
\text { turation, spirituality) } \\
\text { Social resources (e.g., social support, effective parent- } \\
\text { ing, positive peer relations, adult role models) } \\
\text { Early stressful life experiences ("stress potentiation") }\end{array}$ \\
\hline $2 \mathrm{e}, 4 \mathrm{c}$ & Physiological, and health behavior pathways & Cumulative disease risk & $\begin{array}{l}\text { Early biological damages (e.g., impaired or delayed } \\
\text { growth, physiological "programing", compromised } \\
\text { immune functions) } \\
\text { Genetic polymorphisms }\end{array}$ \\
\hline
\end{tabular}

stressful experiences on adolescent biological, behavioral, and psychosocial resource pathways, in the present review we highlight the impact of multiple risk exposure on cumulative disease risk.

\section{Early Socioeconomic Adversity and Cumulative Physical Disease Risk}

We focus on cumulative physical disease risk in young adulthood (see the bolded boxes in Fig. 1) partly because the consequences of various early socioeconomic disadvantages and stressful contexts are typically non-specific and not limited to one particular disease. Factors that contribute to an increased risk of developing one disease often overlap considerably with the risk of developing a number of other physical diseases. Consequently, the impacts of early social disadvantage may be underestimated in disease-specific studies (Aneshensel 2005). Thus, in the present review, we focus broadly on physical disease risk in young adulthood, paying particularly attention to a range of cardiovascular and metabolic disease risks, because these increase significantly during the transition from adolescence to young adulthood (Wickrama et al. 2015). Moreover, our focus on cumulative physical disease risk is consistent with research on multiple system dysregulation, which we highlight in the present review.

\section{Early Adversity and Brain Development and Neuroplasticity}

The brain is the primary mediator of the pathways in our heuristic research framework because, in part, childhood and early adolescence is a critical time of significant brain growth and cognitive skill development (Lupien et al. 2009). Furthermore, three of the four pathways proposed are linked directly to brain development and neuroplasticity, and these pathway associations are bi-directional, and often simultaneous, with brain functioning impacting and 
being impacted by trajectories of psychosocial resources, physiological functioning, and health behavior/mental health. Childhood/adolescence is a sensitive period for many aspects of brain development (Knudsen 2004), which can be impeded by stressful life experiences. As depicted by path $\mathrm{ABC}$, a number of previous studies have provided evidence that childhood socioeconomic adversity, particularly family poverty and parental neglect, detrimentally influence neurobiological development and neurocognitive functioning in the brain (Duncan and Brooks-Gunn 1997; Gunnar and Vasquez 2006; Kishiyama et al. 2009; McEwen 2012; Shonkoff et al. 2009). Also, studies have documented that children raised in family environments characterized by low SES and neglect exhibit growth abnormalities in various regions of brain (e.g., hippocampus and amygdala) (De Bellis et al. 1999; Grassi-Oliveira et al. 2008). Compared to other children, children raised in these environments also average less grey matter in these brain regions (Gianaros et al. 2007; Hanson et al. 2011) and a lower brain volume (Noble et al. 2012). These brain deficiencies are important because several studies suggest that disruptions in brain development and brain functioning during childhood may have long-term implications for stress sensitivity and for behavioral and psychosocial resource trajectories (paths 2c, 3b, and 4b).

Even in adolescence, the brain is not a "finished product" (Konrad et al. 2013). Brain maturation continues during adolescence, particularly the acquisition of higher order functions, such as decision making and impulse control (Gogtay et al. 2004; Lopez et al. 2008). Furthermore, "an imbalance in maturation" of the brain during adolescence has been noted because the subcortical area develops earlier than the prefrontal area (Konrad et al. 2013). This imbalance may result in heightened sensitivity to rewards and reduced sensitivity to goal-directed behavior, which may help explain why adolescence is often a time of increased risk-taking behavior, along with the more normative and adjustive nature of risk taking during this developmental period (Moffitt 1993). However, as in childhood, adolescent brain maturation is also influenced by the environment. For example, a recent longitudinal study found that years lived in poverty across ages 11-18 forecasted diminished hippocampal and amygdala volumes in young adulthood for a control group; however, these effects were ameliorated in a group receiving a family based intervention designed to enhance supportive parenting at age 11 (Brody et al. 2016).

\section{The Early Biological/Genetic Vulnerability Pathway (Pathway 1 in Fig. 1)}

Previous studies have documented the mediating and moderating roles of early biological vulnerabilities, such as low birth weight, pre-term birth, physiological damages, and genetic vulnerability, in relation to the early adversity-health connection (Goodman et al. 2005; Miller et al. 2011; Packard et al. 2011; Repetti et al. 2011). With regard to these mediating influences, early stressful experiences biologically program developing physiological systems, beginning even in utero, and can cause physiological damages (Smith et al. 1997) as depicted by path 1a. Furthermore, because these physiological changes get "under the skin" during this sensitive developmental period (i.e., become irreversible and incubate), they can also compound and accumulate creating adverse trajectories of physiological changes resulting in disease risk years later as depicted by path 1d (Hertzman and Boyce 2010; Miller et al. 2011; Packard et al. 2011; Shonkoff et al. 2009). For example, escalating trajectories of blood pressure from childhood to young adulthood are influenced by adverse childhood experiences (Su et al. 2015). Also, coronary heart disease, hypertension, stroke, and diabetes in adulthood can be traced back to low birth weight and low growth rate in early infancy regardless of adult social status (Barker 1998; Barker et al. 1989; Forsén et al. 1997). Manifestations of this health impact are sometimes obvious in adolescence as well, as evidenced by early elevated levels of regulatory biomarkers, such as blood glucose level and BMI (Goodman et al. 2005). It has also been demonstrated that harsh family environments trigger a proinflammatory phenotype in children, which contributes to the development of chronic diseases as they age (Miller and Chen 2010).

Early biological vulnerabilities also influence the development and consolidation of individual psychosocial resources (or vulnerabilities) (path 1c). For example, low birth weight is associated with low self-esteem, reduced mastery, inhibited psychological and behavioral control, poor educational performance, and poor social relations (Lund et al. 2012; Ribeiro et al. 2011). In turn, these resources are negatively associated with young adult disease risk (path $3 \mathrm{~d}$ ), which we will discuss in detail in a later section.

With regard to moderating influences, early damages and impairments in physiological regulatory systems, as presented in Table 2, may amplify the health impact of experiencing adolescent stressors (Loman and Gunnar 2010; Repetti et al. 2011), as well as of other pathways (e.g., physiology and health risk behavior) leading to subsequent disease risk because early physiological damages (e.g., physiological "programming" including compromised immune functions) increase youth's health vulnerability (Godfrey and Barker 2001). For example, children's heightened heart-rate reactivity amplifies the health influence of daily stressors (Gannon et al. 1989). 


\section{Gene Expression, Genetic Vulnerability}

In this review, genetic vulnerability is conceptualized as a part of early vulnerability or biological imbedding (Hertzman and Boyce 2010) because genetic disposition can be turned off or on depending on early life experiences (Non et al. 2016; Meaney 2010) (path 1a). That is, epigenetic research has shown that experiences, such as adversity, are related to how genes are "expressed" (i.e., phenotypes), and this genetic expression is a determining factor of emotional and behavioral problems (path 1b), psychosocial resources (path 1c), and disease risk (path 1d).

Genetic polymorphisms are variations in the structure of genes, and each variant of a gene is called an "allele". Most molecular genetic research on youth behavior has focused on genetic variations that regulate neurotransmitter systems, such as serotoninergic and dopaminergic neurotransmitter systems. We limit our review to a handful of these alleles or "candidate genes" that have been frequently studied (e.g., 5-HTT, DRD2, DRD4). 5-HTT is a key regulator of serotoninergic neurotransmission (implicated in reward sensitivity). Individuals with one or two copies of the 5-HTT "short" allele display more behavioral and psychological difficulties (path 1b) as well as health problems (path 1d) (Gloster et al. 2015; Wargelius et al. 2012). The DRD2 candidate gene is linked to regulating the dopaminergic system (implicated in sensitivity to pleasure and punishment) (DeYoung et al. 2005), and youth with the A1 allele of DRD2 are more likely to encounter difficulties in close relationships (path 1c) (Waldman 2007; Walum et al. 2008). Furthermore, studies have shown that genetic influence increases over the early life course making genetic vulnerabilities more relevant during adolescence than childhood (genexage interaction) (Shanahan and Boardman 2009).

\section{Genetic Moderation}

More importantly, as presented in Table 2, genetic polymorphisms may interact with stressful (or positive) life contexts to impact youth behavioral and mental health trajectories (moderation of path 4a), psychosocial resource outcomes (moderation of path 3a), and physiological outcomes (moderation of paths $2 b$ and $2 c$ ). These gene-environment interactions are known as $\mathrm{G} \times \mathrm{E}$ effects. In addition, genetic differences may modify the effect of health risk behavior (e.g., alcohol use, eating behavior) on disease risk (e.g., risk of heart disease and obesity) (representing moderation of path 4c) (Corella et al. 2001; Loktionov et al. 2000).

The 5HTTLPR polymorphism of the 5-HTT gene is one of the most extensively studied genetic variants in $\mathrm{G} \times \mathrm{E}$ developmental studies and has been shown to moderate the influence of adolescents' stressful life events on their depressive symptoms (Caspi et al. 2003). The 5HTTLPR allele may also interact with early socioeconomic adversity to influence youth educational attainment, the occurrence of "off-time" life events, and cardiovascular and metabolic disease risk (Wickrama et al. 2016). Other research has shown that the influence of community adversity on adolescent BMI trajectories is greater for those with more sensitivity alleles (e.g., 5HTTLPR, DRD4) than those with fewer sensitivity alleles (Wickrama et al. 2013). Similarly, emerging adults manifest steeper escalating trajectories of drug use when they report a high level of life stress and carry an allele of DRD4 (Brody et al. 2012).

Although research has shown that this polymorphism produces adverse outcomes under stressful contexts (i.e., a diathesis hypothesis), the same gene may also act more generally to enhance environmental sensitivity; thereby producing positive youth outcomes in positive contexts (i.e., genetic plasticity) (Simons and Lei 2013; Wickrama and O'Neal 2015). Furthermore, multiple genes may cumulatively influence youth health and behavioral outcomes (i.e., shared genetic influence) (Belsky and Beaver 2011). Accordingly, individual differences in youth genetic disposition may partially shape developmental pathways beyond socioeconomic adversity (Belsky and Beaver 2011; Simons and Lei 2013; Wickrama and O’Neal 2015).

\section{The Physiological (Stress-Neuroendocrine) Pathway (Pathway 2 in Fig. 1)}

As depicted by paths $2 \mathrm{~b}$ and $2 \mathrm{c}$, the physiological pathway involves the mediating role of the brain in relation to the association between adolescent stressors and stress responses that lead to neuroendocrine hormonal activation (Ganzel et al. 2010; McEwen and Gianaros 2010; Seeman et al. 2010). Over time, repeated and/or continuous stress responses lead to physiological dysregulation through neuroendocrine responses including activity in the hypothalamic-pituitary-adrenal (HPA) axis and the sympatheticadrenal-medullary (SAM) axis because these systems fail to adapt to future stressors. That is, although neuroendocrine hormonal activation may be protective insofar as it provides short-term adaption (i.e., allostasis), if the activation is excessive, it may contribute to physiological dysregulation in multiple biological systems (i.e., allostatic load), eventually leading to diseases with protracted etiologies (Matthews and Gallo 2011; McEwen and Gianaros 2010; Seeman et al. 2010) (path 2e).

Early stressful life contexts increase the likelihood that youth will encounter stressors later in adolescence and young adulthood in a successively contingent manner over adolescence, creating a stress trajectory or pathway (path 2a) (Attar et al. 1994; O'Rand and Hamil-Luker 
2005). For instance, stressful life contexts encountered in childhood and adolescence, such as family economic hardship, parents' marital conflict, or community adversity often increase the likelihood that these youth will face additional hardship (e.g., Conger et al. 2002; ElSheikh et al. 2013; Wickrama et al. 2005). The resulting stress trajectories may include the early onset of puberty (Ge et al. 2001), adolescent stressful life events and circumstances (Wickrama et al. 2015b), romantic relationship problems (Barr et al. 2016), and an off-time (early or late) transition to adulthood, including the acquisition of adult roles such as becoming a parent, cohabiting, and dropping out of school (Lee 2015; Wickrama et al. 2015a, 2005). Furthermore, off-time events and the related adverse transition patterns are chronically stressful for youth because they often create a "rush to adulthood" for which the adolescent is often not emotionally, financially, and socially/relationally prepared (Foster et al. 2008; Lee 2015; Wickrama et al. 2010).

As depicted by paths $2 \mathrm{~b}$ and $2 \mathrm{c}$ and also detailed in Fig. 2, adolescent stressors invoke physiological responses that produce various neuroendocrine hormones (Packard et al. 2011). That is, the neurocognitive stress process is mediated by the brain as it translates environmental stimuli (e.g., an adolescent stressor) into stress responses (Ganzel et al. 2010; McEwen 2012; McEwen and Gianaros 2010). First, the brain processes information about the stressor, including an appraisal of the threat. Second, the brain regulates the stress response by invoking neuroendocrine activation.
Fig. 2 The stress-physiological pathway: from adolescent stressor to physiological dysregulation in multiple systems

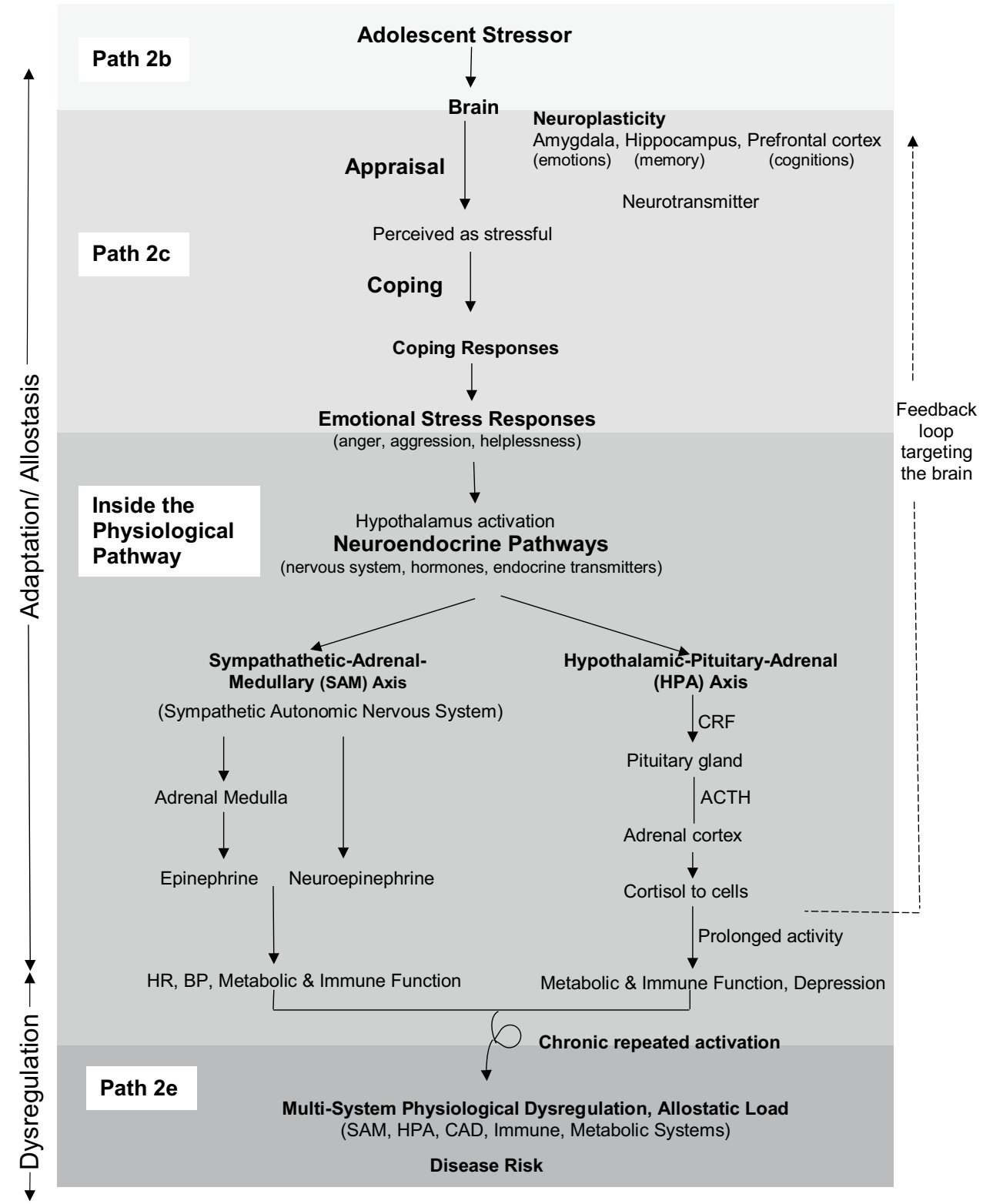




\section{Neuroendocrine Systems}

As illustrated in Fig. 2, the primary regulatory systems include the sympathathetic-adrenal-medullary (SAM) axis and the hypothalamic-pituitary-adrenal (HPA) axis (Seeman et al. 2010). When these systems are activated, they produce various neuroendocrine hormones, such as cortisol, epinephrine, and neuroepinephrine, which aid in productive short-term adaptations to stress.

However, exorbitant physiological stress responses (e.g., the excessive production of hormones through the HPA axis and SAM reactivity) are contemporaneously and longitudinally associated with adolescent emotional and behavioral problems (path $2 \mathrm{~d}$ in Fig. 1) (Hastings et al. 2011; Seeman et al. 2010). In particular, changes in hormone levels associated with puberty have negative behavioral and mental health outcomes for adolescents (Blakemore et al. 2010), and variations in cortisol levels are linked to adolescent alcohol use (Ruttle et al. 2015).

Although these stress responses are thought to be adaptive as the body attempts to maintain stability through change (i.e., allostasis), chronic arousal of the brain and excessive activation of physiological systems can lead to cumulative physiological dysregulation in multiple systems (path 2e). This is because, as shown in Fig. 2, primary regulatory systems are associated with additional peripheral systems, including metabolic and cardiovascular systems as well as the immune system (inflammation); all of which are inter-related (Seeman et al. 2010). Particularly, hormonal activation, such as impaired endothelial functions, may mediate the stress and inflammation (impaired immune function; e.g., elevated levels of C-reactive protein) association (Black 2002) as well as the connection between stress and cardiovascular dysregulation (Ghiadoni et al. 1998). Physiological dysregulation establishes new baseline parameters of these regulatory systems (e.g., elevated blood pressure or blood glucose) (Boulos and Rosenwasser 2004; McEwen 1998; Seeman et al. 2010). For instance, low socioeconomic trajectories from adolescence to adulthood (where SES is defined as parental occupation and then their socioeconomic attainment) are related to long-term cortisol dysregulation (Gustafsson et al. 2010). Taken together, prior literature has provided strong evidence of the brain operating as a mediator between adolescent stressors and stress responses that lead to chronic levels of neuroendocrine hormonal activation with detrimental effects on a host of biological systems.

\section{The Brain as a Target of the Stress Process}

Recent stress response models emphasize that dysregulation in multiple systems can also create wear and tear on the brain as depicted by the left-directed arrow of path $2 \mathrm{c}$ in Fig. 1. That is, the association between brain and physiological systems via neural and endocrine mechanisms work in both directions (Ganzel et al. 2010; McEwen and Gianaros 2010). For example, excessive production of stress hormones (e.g., cortisol) can affect the structure of brain regions and their functions resulting in changes in memory formation and memory deficits (Gould et al. 1997; Sapolsky 2000). Additionally, stress hormones associated with early socioeconomic adversity may deleteriously alter the functional connectivity among regions of the adolescent brain. Specifically, it has been demonstrated that, for females, higher socioeconomic adversity in the first year of life predicted higher subsequent cortisol levels, which were a determinant of decreased resting state functional connectivity between the amygdala and components of the prefrontal cortex at age 18 (Burghy et al. 2012). Thus, the brain is not only the primary mediator of the stress process but also a central target of the same stress process.

\section{The Moderating Effect of Early Stressful Life Contexts: Stress Potentiation}

Previous developmental research has suggested childhood/adolescent stressful contexts moderate several of the pathways illustrated in Fig. 1. Early stressful life experiences (e.g., stressful parent-child relationships, parental disconnection, lack of nurturing), which can also continue into adolescence, may result in heightened stress sensitivity, impaired self-regulation, and impaired coping mechanisms; all of which are implicated in increased disease risks (Dich et al. 2015; Loman and Gunnar 2010; Lovallo 2013; Repetti et al. 2011; Shonkoff et al. 2012; Bae and Wickrama 2017). That is, early stressful contexts not only influence the occurrence of later, adolescent stressors (path 2a), but also amplify the health effect of these later stressors through paths $2 \mathrm{~b}, 2 \mathrm{c}$, and $2 \mathrm{e}$. This stress amplification is also known as stress potentiation (Loman and Gunnar 2010; Lovallo 2013; Shonkoff et al. 2012).

Moreover, neurobiological studies have shown that neurological processing of stressful life contexts and current stressors occur in different parts of the brain's emotional circuitry (Armony and LeDoux 1997) suggesting stressful life contexts (e.g., parental rejection) and stressful life events are two psychologically distinct constructs. Thus, they may have unique impacts on health outcomes through differential processes (Dich et al. 2015; Lovallo 2013; McCutcheon et al. 2010) and these processes may interact with each other to further influence health outcomes. 


\section{The Psychosocial Resource (or Vulnerability) Pathway (Pathway 3 in Fig. 1)}

Previous studies have documented that intra- and interpersonal resource (or vulnerability) trajectories mediate the association between early socioeconomic adversity and young adult disease risk (paths $3 \mathrm{a}, 3 \mathrm{~b}$, and $3 \mathrm{~d}$ in Fig. 1) (Zilioli et al. 2016). More importantly, as acknowledged in Table 2, there are moderating effects of intra- and inter-individual resources on behavioral and physiological pathways.

Developmental studies have documented that early socioeconomic conditions adversely influence the development of psychosocial resources (Donnellan et al. 2009; Whitbeck et al. 1991). Early adversity increases adaptive challenges faced by adolescents who are already dealing with the normative biological, cognitive, and social changes that occur during this life stage (Cicchetti and Rogosch 2002; Conger et al. 1994; Harter 2012; Hildyard and Wolfe 2002; Steinberg 2008). In particular, lower-SES parents are more likely to lack necessary financial and material resources and parental knowledge, utilize a harsher, authoritarian, and rejecting parenting style, and engage in parental neglect and abuse. All of these adverse circumstances have been shown to impair the developmental trajectories of cognitive processing capacity and emotional regulation capacity as well as trajectories of educational attainment, mastery, selfesteem, and future orientation (e.g., Farley and Kim-Spoon 2015; Hampson et al. 2007; Hardy 2006; Melby et al. 2008; Nam and Huang 2009; Oshri et al. 2016; Steinberg 2001; Zhang 2003).

Path 3a also depicts the influence of early socioeconomic adversity on the development of personality traits in adolescents. Socioeconomically disadvantaged youth may lack the environmental exposure and interactions necessary to develop positive personality characteristics implicated in socially desirable beliefs and behaviors. Thus, compared to other youth, socioeconomically disadvantaged youth are more likely to be less agreeable, less conscientious, and have high negative emotionality (Conger et al. 2010; Jonassaint et al. 2011). Furthermore, neuroticism and extraversion are associated with inflammation biomarkers while openness is negatively associated with inflammation biomarkers (Armon et al. 2013).

\section{Health Impacts of Psychosocial Resources}

Psychosocial resources are relevant for young adults' disease risk (path 3d). For example, research has shown that psychosocial resources, such as education and self-esteem, have health-protective biological correlates, including a lower cortisol level, better ambulatory heart rate, reduced cardiovascular stress reactivity, and lower rate of disease
(Steptoe et al. 2008, 2005). This may be attributed to increased access to health resources and services (Ross and Mirowsky 2010). This direct path also suggests a neurophysiological mechanism (Zilioli et al. 2016); in that, the association between psychosocial resources and lower disease risk may operate through enhanced brain functioning or increased resiliency to stress (e.g., Center on Social Determinants of Health 2008) (as depicted by the downward arrow of path $3 b$ ).

Additionally, maladaptive psychosocial developmental outcomes, such as impaired self-regulation, delayed discounting, increased impulsivity, and low self-esteem, are associated with various health risk behaviors in adolescence, particularly substance use, risky sexual behavior, and physical inactivity (e.g., Farley and Kim-Spoon 2015; Kogan et al. 2015; Oshri et al. 2016) (not shown in Fig. 1). Further still, there may be even more cascading consequences as previous literature has provided evidence that adolescents with impaired self-regulation are more likely to be caught in "snares", which result in a greater likelihood of being trapped in harmful lifestyles during adulthood (see the downward pointing arrow of path 3c) (Moffitt et al. 2011).

\section{Moderating Effect of Psychosocial Resources}

Consistent with the traditional stress process model (Pearlin et al. 2005), and as depicted in Table 2, psychosocial resources can moderate the influence of early socioeconomic adversity on adolescent stress trajectories (path 2a) and adolescent health behavior and mental health trajectories (path $4 \mathrm{a}$ ).

The moderation of path $2 \mathrm{a}$ may be attributed to the fact that individual psychological resources, such as sense of control and self-regulation, aid in avoiding situations that increase the likelihood of stressful events and circumstances. Even when stressful events occur, psychosocial resources may moderate the stress response (depicted by paths $2 \mathrm{~b}$ and $2 \mathrm{c}$ ) because individuals with psychosocial resources are generally more proactive in seeking solutions to problems and less traumatized by the occurrence of negative events (Pearlin et al. 1981). Furthermore, social resources appear to be moderators of the genetic influence on health behaviors (path 1b). For example, involved parenting attenuates the link between the 5-HTT gene and substance use (Brody et al. 2009). Conversely, psychological vulnerability, as manifested by a lack of psychosocial resources, amplifies the adverse health influence of stressful life circumstances (King et al. 2015).

However, individual psychosocial characteristics are not fully shaped by socioeconomic adversity (as suggested by path 3a). Instead, a substantial number of adolescents possess healthy levels of psychosocial resources regardless of their 
socioeconomic background; these adolescents are capable of leveraging resources to successfully negotiate life challenges in a manner that allows them to altogether avoid, or at least minimize the detrimental impact of, many of the stressors encountered by youth who lack these psychosocial resources stressors (Bonanno 2005; Freitas and Downey 1998; Luthar et al. 2000; Rutter 1999). This represents the resilience of a number of youth who are able to develop psychosocial resources in the face of early adversity. This point is important because this resilience epitomizes why all children born into socioeconomic disadvantage are not destined to experience disease or other negative outcomes.

Furthermore, psychosocial resources also serve as a source of resilience, as these resources allow youth to thrive, or at least avoid more detrimental effects experienced by others, when faced with adversity. For instance, as illustrated in Table 2, adolescent stressors, such as relationship difficulties, are likely less detrimental for the mental health and behavioral health of youth with more psychosocial resources (e.g., self-esteem, mastery, etc). As previously noted, this stress resiliency may also be attributed to the association between psychosocial resources and enhanced brain functioning. Researchers contend that low SES youth who are exposed to positive role models may develop appropriate emotion regulation behaviors in the face of stress while fostering a future orientation because positive role models provide the stable attachment relationships that are necessary for promoting this positive development (Chen and Miller 2012). This allows youth to "shift" themselves in the face of immediate stressors while "persisting" in the broader perspective of life (i.e., a "shift and persist" strategy). Thus, these low-SES youth are less likely to display heightened physiological responses to stressors.

However, recent studies have shown that striving for psychosocial achievement (e.g., educational attainment) in the face of adverse socioeconomic conditions during adolescence may exert a physiological toll on youth years later as young adults (Brody et al. 2013; Wickrama et al. 2016b). This problematic moderating effect of social achievement is consistent with the John Henryism hypothesis, which suggests that positive developmental achievement in the presence of adversity often requires intense physical, mental, and/or social effort (see James 1994 for a detailed explanation of the hypothesis). Such intensity is often stressful and, consequently, increases the risk of disease.

\section{The Behavioral and Mental Health Pathway (Pathway 4 in Fig. 1)}

As shown by paths $4 \mathrm{a}, 4 \mathrm{~b}$, and $4 \mathrm{c}$ in Fig. 1, health risk behaviors, including substance use, poor eating habits, a sedentary lifestyle, and risky sexual behavior, as well as poor mental health trajectories mediate the association between early socioeconomic adversity and youth disease risk. In addition, the physiological pathway connects early socioeconomic adversity to emotional and behavioral problems through various paths (e.g., the downward pointing arrow of path 2d). That is, research suggests that these associations operate through both neurophysiological and structural mechanisms.

Regarding structural mechanisms, numerous studies have found that family and community socioeconomic characteristics influence an individual's health behaviors (path 4a) (Shin and Miller 2012). Adolescents from poor families often lack health resources, including access to healthy food, recreation facilities, and health services (Fitzgibbon et al. 1998). Furthermore, disadvantaged parents often transmit their unhealthy behaviors and risky lifestyles to their offspring (Wickrama et al. 1999). Poor families are often located within poor communities, which further hinders healthy behaviors because these communities are often unable to meet their residents' dietary and health-related needs. For example, not only do unaffordable prices limit access to healthy foods in poor communities, but poor communities also have a greater number of unhealthy fast food restaurants compared to higher income communities (Kipke et al. 2007). Disadvantaged communities also often lack recreational activities, safe spaces for engaging in physical activities, and nearby health services (Wen and Maloney 2011). Studies have also documented the lack of social resources in disadvantaged communities. The lack of community support, positive role models, and close relationships, act as deterrents for a healthy lifestyle while simultaneously encouraging risky healthy behaviors (Umberson et al. 2008; Wickrama and O'Neal 2015).

Family and community adverse conditions and ethnic minority status also increase youth's risk for emotional problems (path 4a). A lack of physical and/or social resources and opportunities associated with socioeconomic adversity combined with a threatening community environment, poor housing, and related physical hazards as well as racial discrimination often lead adolescents to feel trapped, angry, hopeless, and frustrated (Brody et al. 2006; Prawitz et al. 2013; Ross et al. 2000; Wickrama and Bryant 2003). These negative feelings make youth more susceptible to developing emotional and behavioral problems, such as depressive symptoms, substance use, and risky sexual activities (Kerrigan et al. 2006; Kogan et al. 2010; Wheaton and Clarke 2003). Using growth mixture modeling, previous studies have shown that youth depressive symptoms trajectories are socially stratified, and adverse depressive symptoms trajectories are associated with various health risk behaviors including risky sexual activity, crime, and substance use (Wickrama et al. 2016a, 2010). Furthermore, 
these negative feelings play a role in the adoption of health risk behaviors (Browning and Cagney 2003; Kogan et al. 2010). Research has shown that emotional eating (eating more foods that are high in fat and less fruits and vegetables) is often utilized by distressed individuals as a coping mechanism for experiencing negative emotions (Macht 2008; Macht et al. 2005).

Behavioral trajectories are also influenced by brain development and functioning in childhood (path $4 \mathrm{~b}$ ). Also, heightened reward sensitivity during adolescence may contribute to risk taking in the form of risky health behaviors, particularly substance use (Chambers et al. 2003; Chein et al. 2011; Steinberg 2004). However, recent studies have shown that heightened reward sensitivity in adolescence may decrease risk taking behaviors if adolescents are engaged in prosocial activities (Telzer et al. 2013). Conversely, psychosocial resources, such as positive affect, self-regulation, self-esteem, social integration, and education reduce the likelihood of youth engaging in health risk behaviors. For example, extant literature has demonstrated that higher reward sensitivity is associated with earlier onset of substance use for adolescents with low inhibitory control (measured via both behavioral and neural indicators), but not among adolescents with high inhibitory control (Kim-Spoon et al. 2016). This association may be attributed to a neurological mechanism as enhanced brain functioning is associated with psychosocial resources (the downward pointing arrowing of path $3 b$ ).

In addition, as depicted by the downward pointing arrow of path $2 \mathrm{~d}$, physiological stress responses, such as elevated levels of stress hormones, also have behavioral and emotional consequences, including the consumption of an overall less healthy diet, a sedentary lifestyle, and alcohol use (Konttinen et al. 2010; Ruttle et al. 2015). Conversely, as depicted by the upward pointing arrow of path $2 \mathrm{~d}$, there are physiological consequences of elevated levels of depressive and anxiety symptoms (Culpepper 2009; Fagundes et al. 2013). Also, as depicted by the left-directed arrow of path $4 \mathrm{~b}$, health risk behaviors (e.g., ongoing adolescent substance use) impair brain functioning (for a review see Squeglia et al. 2009).

As depicted by path $4 \mathrm{c}$, it is well documented that health risk behaviors and poor mental health increase youth disease risk (Culpepper 2009; Raposa et al. 2015). For example, studies suggest that the consumption of a less healthy diet, physical inactivity, and sedentary behavior contribute to an increased risk for metabolic diseases, including obesity and diabetes (Biro and Wien 2010; Steyn et al. 2004). More importantly, these unhealthy behaviors have been shown to have proinflammatory effects related to disease risk (Stringhini et al. 2013). Furthermore, psychobiological research has shown that elevated depressive, anxiety, and hostility symptoms also contribute to increased disease risk through dysregulation of physiological regulatory systems (the upward arrow of paths 2d and 2e) (Culpepper 2009; Fagundes et al. 2013).

\section{Discussion}

The SADR model draws heavily from recent studies on the stress process in adulthood and identifies the brain as a mediator, as well as a primary target, of the stress process. Consequently, our review led to the conclusion that the physiological pathway involving the brain plays the most prominent mediating role linking early and adolescent stressors to young adult disease risk. The prominence of this mediating pathway may be specific to adolescence as it is a time of rapid physical and cognitive development. To further explore this possibility, there is a need for more neurodevelopmental research focused specifically on adolescence while investigating these reciprocal influences in the context of brain development and maturation, especially given the cascading influence of these processes over the rest of the lifespan.

The current review emphasizes several important aspects for future research on youth's health outcomes. Across all of these avenues for future research is the need for more advanced cutting-edge analytical techniques involving multi-level data and longitudinal repeated measurements. First, future research investigating multiple dimensions of early socioeconomic adversity is needed. Such research should including both additive and multiplicative health impacts of multilevel factors (e.g., family, race, community) and should also capture both negative (e.g., ineffective parenting, community disorganization) and positive (e.g., effective parenting, collective socialization, and community affluence) dimensions of adversity. Similarly, there is also a need for future research incorporating both stress and resource pathways leading to young adult health outcomes. Second, future research should properly integrate the pathways proposed here, which include capturing psychosocial, biological (biomarkers), genetic (genetic polymorphism), and neurological changes simultaneously, within a "long view" perspective utilizing prospective data. Third, in addition to conducting research assessing additive and linear influences of these pathways, future research should focus on the multiplicative health influences of different pathways (e.g., health impact of conjoint mental health and physiological trajectories). Fourth, there is a need to identify additional modifiers of these pathways that are specific to adolescence. While the framework identifies the moderating effects of socioeconomic contexts and psychosocial resources on the physiological and behavioral pathways to accumulated disease risk (see Table 2), studies of these 
moderating effects are somewhat underdeveloped, particularly as they relate to adolescence.

The material and biopsychosocial pathways that we discussed in the current review stem from early socioeconomic adversity and lead to young adult health inequalities. That is, in many instances, an early stressful socioeconomic context appears to be a primary impetus for subsequent health inequalities in young adults. Such a model, then, suggests the need for macro-level policy formulations and early prevention strategies addressing early socioeconomic adversity itself (Center on Social Determinants of Health 2008). These strategies are in addition to the previously discussed resilient, modifiable pathways that serve as potential local and grass-root level intervention points. Thus, federal, state, and county level policies and programs should be designed to reduce socioeconomic disadvantage and inequalities as this offers a strong preventative method for inoculating against the consequences of an early stressful context. More specific policies and programs are likely to develop from research testing aspects of the current heuristic organizing framework.

Relatedly, there is a need for additional interventions aimed at reducing the impact of early adversity on the initial levels and shapes of physiological, behavioral, and resource trajectories. It is imperative that the efficacy of such interventions be assessed so successful interventions can be adopted more broadly. For example, family-based interventions, such as the Family Check-Up (Fosco et al. 2013) and Strong African American Families program (Brody et al. 2016), have demonstrated efficacy in reducing exposure to early life adversities while positively altering said trajectories. Implementing interventions to reduce experiences of early adversity may also be able to ward off early biological damages with long-term health impacts.

This review study also brings to light several important practical implications for interventions targeting early socioeconomic adversity and subsequent health disparity outcomes. First, interventions should aim to target physiological mechanisms as well as the associated behavioral mechanisms (e.g., promoting proper eating habits and physical activity) earlier in the life course because infancy and childhood have been identified as life stages that are more malleable to positive influences in (e.g., parental attachment, cognitive stimulation). Targeting these mechanisms at earlier life stages can effectively reduce the incidence and severity of health risks in later years. Interventions focused on early brain development (Tomporowski et al. 2011), which is influenced by early socioeconomic context, are likely to have long-term positive effects. Such programs that work with parents to foster brain development in their young children can prevent and minimize early physiological damages and aid healthy physical and brain development. Also, the current review highlights the intervention and prevention opportunities stemming from the psychosocial mechanism, which includes self-control, mastery, and self-esteem, and related opportunities for intervening with family processes, including affective parenting and close relationships. In addition to operating as a linking mechanism, interventions targeting the psychosocial mechanism may prove particularly efficacious because psychosocial resources appear to be a primary moderator of multiple pathways responsible for the adversity-health association. Because these psychosocial resources can bolster resilience to adversity, psychosocial resources represent a protective factor that can be leveraged to buffer youth who do encounter socioeconomic adversity from experiencing its negative consequences. More applied research is necessary to identify promising procedures for impeding in the adversityhealth association. In many instances, such procedures may already be active in prevention/intervention projects in various settings (churches, schools, community centers).

\section{Conclusion}

The SADR model illustrated in Figs. 1 and 2 and Tables 1 and 2 serves as a heuristic organizing framework combining past empirical and theoretical evidence and calls for an integrated perspective taking a long-view over the early life course to explain disease risk by combining knowledge from developmental, social, neurocognitive, and biological sciences. The present review does not discuss specific mechanisms in an in-depth manner; instead, it identifies a broad comprehensive framework comprising four overarching pathways: early biological damages/epigenetic regulation as well as physiological, psychosocial, and health behavior/mental health mechanisms linking early socioeconomic adversity to subsequent physical disease risk. Our objective in creating the SADR model, as a comprehensive framework, is to provide a foundation for research conceptualizing physical health risk and its determinants, as well as moderators of these associations, more broadly in order to more accurately assess the various pathways implicated in physical health risk. Such comprehensive research accounts for multiple pathways simultaneously and considers adolescence as a life stage with deep connections to both preceding and following stages rather than an isolated period of development. Such research can have long-lasting implications for advancing the field's understanding of adolescent development.

Author Contributions KASW conducted the comprehensive literature review, conceived the model, and drafted the manuscript; CWO participated in reviewing the literature, constructing and organizing the model, and manuscript preparation; $\mathrm{CH}$ provided neurobiological and psychological expertise. All authors read and approved the final manuscript. 


\section{Compliance with Ethical Standards}

Conflict of interest The authors declare that they have no conflict of interest.

Ethical approval All procedures performed in studies involving human participants were in accordance with the ethical standards of the institutional and/or national research committee and with the 1964 Helsinki declaration and its later amendments or comparable ethical standards.

Informed consent Informed consent was obtained from all individual participants included in the study.

\section{References}

Anda, R. F., Felitti, V. J., Bremner, J. D., Walker, J. D., Whitfield, C. H., Perry, B. D., \& Giles, W. H., et al. (2006). The enduring effects of abuse and related adverse experiences in childhood. European Archives of Psychiatry and Clinical Neuroscience, 256(3), 174-186.

Aneshensel, C. S. (2005). Research in mental health: Social etiology versus social consequences. Journal of Health and Social Behavior, 46(3), 221-228.

Armon, G., Melamed, S., Shirom, A., Berliner, S., \& Shapira, I. (2013). The associations of the five factor model of personality with inflammatory biomarkers: A four-year prospective study. Personality and Individual Differences, 54(6), 750-755.

Armony, J. L., \& LeDoux, J. E. (1997). How the brain processes emotional information. Annals of the New York Academy of Sciences, 821(1), 259-270.

Attar, B. K., Guerra, N. G., \& Tolan, P. H. (1994). Neighborhood disadvantage, stressful life events and adjustments in urban elementary-school children. Journal of Clinical Child Psychology, 23(4), 391-400.

Bae, D., \& Wickrama, K. A. S. (2017). Stress processes linking parent-child disconnection to disease risk in young adulthood: Amplification by genotype. Journal of Youth and Adolescence, 46(5), 1137-1148.

Barker, D. J., Osmond, C., Winter, P. D., Margetts, B., \& Simmonds, S. J. (1989). Weight in infancy and death from ischaemic heart disease. Lancet, 334(8663), 577-580.

Barker, D. J. P. (1998). Mothers, babies and health in later life. Edinburgh: Churchill Livingstone.

Barr, A. B., Sutton, T. E., Simons, L. G., Wickrama, K. A. S., \& Lorenz, F. O. (2016). Romantic relationship transitions and changes in health among rural, White young adults. Journal of Family Psychology, 30(7), 832-842.

Bauman, L. J., Silver, E. J., \& Stein, R. E. (2006). Cumulative social disadvantage and child health. Pediatrics, 117(4), 1321-1328.

Belsky, J., \& Beaver, K. M. (2011). Cumulative-genetic plasticity, parenting and adolescent self-regulation. Journal of Child Psychology and Psychiatry, 52(5), 619-626.

Biro, F. M., \& Wien, M. (2010). Childhood obesity and adult morbidities. The American Journal of Clinical Nutrition, 91(5), 1499 $\mathrm{S}-1505 \mathrm{~S}$

Black, P. H. (2002). Stress and the inflammatory response: A review of neurogenic inflammation. Brain, Behavior, and Immunity, 16(6), 622-653.

Blakemore, S. J., Burnett, S., \& Dahl, R. E. (2010). The role of puberty in the developing adolescent brain. Human Brain Mapping, 31(6), 926-933.
Bonanno, G. A. (2005). Resilience in the face of potential trauma. Current Directions in Psychological Science, 14(3), 135-138.

Boulos, Z., \& Rosenwasser, A. M. (2004). A chronobiological perspective on allostasis and its application to shift work. In J. Schulkin (Ed.), Allostasis, homeostasis, and the costs of physiological regulation (pp. 228-301). Cambridge: Cambridge University Press.

Braveman, P., \& Barclay, C. (2009). Health disparities beginning in childhood: A life-course perspective. Pediatrics, 124(Supplement 3), S163-S175.

Brody, G. H., Gray, J. C., Yu, T., Barton, A. W., Beach, S. R., Galván, A., ... \& Sweet, L. H. (2017). Protective prevention effects on the association of poverty with brain development. JAMA Pediatrics, 171(1), 46-52.

Brody, G. H., Beach, S. R., Philibert, R. A., Chen, Y. F., Lei, M. K. Murry, V. M., \& Brown, A. C. (2009). Parenting moderates a genetic vulnerability factor in longitudinal increases in youths' substance use. Journal of Consulting and Clinical Psychology, $77(1), 1-11$.

Brody, G. H., Chen, Y. F., Murry, V. M., Ge, X., Simons, R. L., Gibbons, F. X., \& Cutrona, C. E., et al. (2006). Perceived discrimination and the adjustment of African American youths: A fiveyear longitudinal analysis with contextual moderation effects. Child Development, 77(5), 1170-1189.

Brody, G. H., Chen, Y. F., Yu, T., Beach, S. R., Kogan, S. M., Simons, R. L., \& Philibert, R. A., et al. (2012). Life stress, the dopamine receptor gene, and emerging adult drug use trajectories: A longitudinal, multilevel, mediated moderation analysis. Development and Psychopathology, 24(3), 941-951.

Brody, G. H., Yu, T., Chen, E., Miller, G. E., Kogan, S. M., \& Beach, S. R. (2013). Is resilience only skin deep? Rural African Americans' socioeconomic status-related risk and competence in preadolescence and psychological adjustment and allostatic load at age 19. Psychological Science, 24, 1285-1293.

Browning, C. R., \& Cagney, K. A. (2003). Moving beyond poverty: Neighborhood structure, social processes, and health. Journal of Health and Social Behavior, 44, 552-571.

Burghy, C. A., Stodola, D. E., Ruttle, P. L., Molloy, E. K., Armstrong, J. M., Oler, J. A., \& Davidson, R. J., et al. (2012). Developmental pathways to amygdala-prefrontal function and internalizing symptoms in adolescence. Nature Neuroscience, 15(12), 1736-1741

Caspi, A., Sugden, K., Moffitt, T. E., Taylor, A., Craig, I. W., Harrington, H., \& Poulton, R. (2003). Influence of life stress on depression: Moderation by a polymorphism in the 5-HTT gene. Science, 301(5631), 386-389.

Center on Social Determinants of Health. (2008). Closing the gap in a generation: Health equity through action on the social determinants of health. Final Report of the Commission on Social Determinants of Health. Geneva, World Health Organization. http://www.who.int/social_determinants/thecommission/finalreport/en/. Accessed 10 Apr 2017.

Chambers, R. A., Taylor, J. R., \& Potenza, M. N. (2003). Developmental neurocircuitry of motivation in adolescence: A critical period of addiction vulnerability. American Journal of Psychiatry, 160, 1041-1052.

Chein, J., Albert, D., O’Brien, L., Uckert, K., \& Steinberg, L. (2011). Peers increase adolescent risk taking by enhancing activity in the brain's reward circuitry. Developmental Science, 14(2), F1-F10.

Chen, E., \& Miller, G. E. (2012). "Shift-and-persist" strategies why low socioeconomic status isn't always bad for health. Perspectives on Psychological Science, 7(2), 135-158.

Cicchetti, D., \& Rogosch, F. A. (2002). A developmental psychopathology perspective on adolescence. Journal of Consulting and Clinical Psychology, 70(1), 6-20. 
Cohen, S., Janicki-Deverts, D., Chen, E., \& Matthews, K. A. (2010). Childhood socioeconomic status and adult health. Annals of the New York Academy of Sciences, 1186(1), 37-55.

Conger, K. J., Rueter, M. A., \& Conger, R. D. (2000). The role of economic pressure in the lives of parents and their adolescents: The family stress model. In L. J. Crockett \& R. Silbereisen (Eds.), Negotiating adolescence in times of social change (pp. 201223). New York, NY: Cambridge University Press.

Conger, R. D., Conger, K. J., \& Martin, M. J. (2010). Socioeconomic status, family processes, and individual development. Journal of Marriage and Family, 72(3), 685-704.

Conger, R. D., Ge, X., Elder, G. H., Lorenz, F. O., \& Simons, R. L. (1994). Economic stress, coercive family process, and developmental problems of adolescents. Child Development, 65(2), 541-561.

Conger, R. D., Wallace, L. E., Sun, Y., Simons, R. L., McLoyd, V. C., \& Brody, G. H. (2002). Economic pressure in African American families: A replication and extension of the family stress model. Developmental Psychology, 38(2), 179-193.

Corella, D., Tucker, K., Lahoz, C., Coltell, O., Cupples, L. A., Wilson, P. W., \& Ordovas, J. M., et al. (2001). Alcohol drinking determines the effect of the APOE locus on LDL-cholesterol concentrations in men: The Framingham Offspring Study. The American Journal of Clinical Nutrition, 73(4), 736-745.

Costello, E. J., Mustillo, S., Erkanli, A., Keeler, G., \& Angold, A. (2003). Prevalence and development of psychiatric disorders in childhood and adolescence. Archives of General Psychiatry, 60(8), 837-844.

Culpepper, L. (2009). Generalized anxiety disorder and medical illness. The Journal of Clinical Psychiatry, 70(suppl 2), 20-24.

Czerwinski, S. A., Lee, M., Choh, A. C., Wurzbacher, K., Demerath, E. W., Towne, B., \& Siervogel, R. M. (2007). Genetic factors in physical growth and development and their relationship to subsequent health outcomes. American Journal of Human Biology, 19(5), 684-691.

Danese, A., Moffitt, T. E., Harrington, H., Milne, B. J., Polanczyk, G., Pariante, C. M., \& Caspi, A. (2009). Adverse childhood experiences and adult risk factors for age-related disease: Depression, inflammation, and clustering of metabolic risk markers. Archives of Pediatrics and Adolescent Medicine, 163(12), $1135-1143$

Dannefer, D. (2003). Cumulative advantage/disadvantage and the life course: Cross-fertilizing age and social science theory. The Journals of Gerontology Series B: Psychological Sciences and Social Sciences, 58(6), S327-S337.

De Bellis, M. D., Keshavan, M. S., Clark, D. B., Casey, B. J., Giedd, J. N., Boring, A. M., \& Ryan, N. D., et al. (1999). Developmental traumatology part II: Brain development. Biological Psychiatry, 45(10), 1271-1284.

DeYoung, C. G., Peterson, J. B., \& Higgins, D. M. (2005). Sources of openness/intellect: Cognitive and neuropsychological correlates of the fifth factor of personality. Journal of Personality, 73(4), $825-858$.

Dich, N., Hansen, A. M., Avlund, K., Lund, R., Mortensen, E. L., Bruunsgaard, H., \& Rod, N. H. (2015). Early life adversity potentiates the effects of later life stress on cumulative physiological dysregulation. Anxiety, Stress, and Coping, 28(4), 372-390.

Donnellan, M. B., Conger, K. J., McAdams, K. K., \& Neppl, T. K. (2009). Personal characteristics and resilience to economic hardship and its consequences: Conceptual issues and empirical illustrations. Journal of Personality, 77(6), 1645-1676.

Duncan, G. J., \& Brooks-Gunn, J. (Eds.). (1997). Consequences of growing up poor. New York, NY: Russell Sage Foundation.

Elder, G. H., \& Giele, J. Z. (2009). The craft of life course research. (Eds.). New York: Guildford Press.
Elder, G. H. Jr., Johnson, M. K., \& Crosnoe, R. (2003). The emergence and development of life course theory. In J. T. Mortimer \& M. J. Shanahan (Eds.), Handbook of the life course (pp. 3-19). New York, NY: Kluwer.

El-Sheikh, M., Keiley, M., Erath, S., \& Dyer, W. J. (2013). Marital conflict and growth in children's internalizing symptoms: The role of autonomic nervous system activity. Developmental Psychology, 49(1), 92-108.

Evans, G. W., \& Kim, P. (2010). Multiple risk exposure as a potential explanatory mechanism for the socioeconomic status-health gradient. Annals of the New York Academy of Sciences, 1186(1), 174-189.

Fagundes, C. P., Glaser, R., Hwang, B. S., Malarkey, W. B., \& Kiecolt-Glaser, J. K. (2013). Depressive symptoms enhance stress-induced inflammatory responses. Brain, Behavior, and Immunity, 31, 172-176.

Farley, J. P., \& Kim-Spoon, J. (2015). Longitudinal associations among impulsivity, friend substance use, and adolescent substance use. Journal of Addiction Research and Therapy, 6(2), e220.

Fitzgibbon, M. L., Spring, B., Avellone, M. E., Blackman, L. R., Pingitore, R., \& Stolley, M. R. (1998). Correlates of binge eating in Hispanic, Black, and White women. International Journal of Eating Disorders, 24(1), 43-52.

Forsén, T., Eriksson, J. G., Tuomilehto, J., Teramo, K., Osmond, C., \& Barker, D. J. P. (1997). Mother's weight in pregnancy and coronary heart disease in a cohort of Finnish men: Follow up study. BMJ (Clinical Research Ed.), 315(7112), 837-840.

Fosco, G. M., Frank, J. L., Stormshak, E. A., \& Dishion, T. J. (2013). Opening the "Black Box": Family Check-Up intervention effects on self-regulation that prevents growth in problem behavior and substance use. Journal of School Psychology, 51(4), 455-468.

Foster, H., Hagan, J., \& Brooks-Gunn, J. (2008). Growing up fast: Stress exposure and subjective "weathering" in emerging adulthood. Journal of Health and Social Behavior, 49(2), 162-177.

Freitas, A. L., \& Downey, G. (1998). Resilience: A dynamic perspective. International Journal of Behavioral Development, 22(2), 263-285.

Gannon, L., Banks, J., Shelton, D., \& Luchetta, T. (1989). The mediating effects of psychophysiological reactivity and recovery on the relationship between environmental stress and illness. Journal of Psychosomatic Research, 33(2), 167-175.

Ganzel, B. L., Morris, P. A., \& Wethington, E. (2010). Allostasis and the human brain: Integrating models of stress from the social and life sciences. Psychological Review, 117(1), 134-174.

Ge, X., Conger, R. D., \& Elder, G. H. Jr. (2001). Pubertal transition, stressful life events, and the emergence of gender differences in adolescent depressive symptoms. Developmental Psychology, 37(3), 404-414.

Ghiadoni, L., Taddei, S., Virdis, A., Sudano, I., Di Legge, V., Meola, M., \& Salvetti, A. (1998). Endothelial function and common carotid artery wall thickening in patients with essential hypertension. Hypertension, 32(1), 25-32.

Gianaros, P. J., Jennings, J. R., Sheu, L. K., Greer, P. J., Kuller, L. H., \& Matthews, K. A. (2007). Prospective reports of chronic life stress predict decreased grey matter volume in the hippocampus. NeuroImage, 35(2), 795-803.

Glass, T. A., \& McAtee, M. J. (2006). Behavioral science at the crossroads in public health: Extending horizons, envisioning the future. Social Science \& Medicine, 62(7), 1650-1671.

Gloster, A. T., Gerlach, A. L., Hamm, A., Höfler, M., Alpers, G. W., Kircher, T., \& Reif, A. (2015). 5HTT is associated with the phenotype psychological flexibility: Results from a randomized clinical trial. European Archives of Psychiatry and Clinical Neuroscience, 265(5), 399-406. 
Godfrey, K. M., \& Barker, D. J. (2001). Fetal programming and adult health. Public Health Nutrition, 4(2b), 611-624.

Gogtay, N., Giedd, J. N., Lusk, L., Hayashi, K. M., Greenstein, D., Vaituzis, A. C., \& Rapoport, J. L., et al. (2004). Dynamic mapping of human cortical development during childhood through early adulthood. Proceedings of the National Academy of Sciences of the United States of America, 101(21), 8174-8179.

Goodman, E., McEwen, B. S., Dolan, L. M., Schafer-Kalkhoff, T., \& Adler, N. E. (2005). Social disadvantage and adolescent stress. Journal of Adolescent Health, 37(6), 484-492.

Gould, E., McEwen, B. S., Tanapat, P., Galea, L. A., \& Fuchs, E. (1997). Neurogenesis in the dentate gyrus of the adult tree shrew is regulated by psychosocial stress and NMDA receptor activation. The Journal of Neuroscience, 17(7), 2492-2498.

Grassi-Oliveira, R., Ashy, M., \& Stein, L. M. (2008). Psychobiology of childhood maltreatment: Effects of allostatic load? Revista Brasileira de Psiquiatria, 30(1), 60-68.

Gunnar, M., \& Vasquez, D. M. (2006). Stress neurobiology and developmental psychopathology. In D. Cicchetti \& D. Cohen (Eds.), Developmental psychopathology (2nd edn.). New York, NY: Wiley.

Gustafsson, P. E., Janlert, U., Theorell, T., \& Hammarström, A. (2010). Life-course socioeconomic trajectories and diurnal cortisol regulation in adulthood. Psychoneuroendocrinology, 35(4), 613-623.

Halfon, N., \& Hochstein, M. (2002). Life course health development: An integrated framework for developing health, policy, and research. Milbank Quarterly, 80(3), 433-479.

Hampson, S. E., Goldberg, L. R., Vogt, T. M., \& Dubanoski, J. P. (2007). Mechanisms by which childhood personality traits influence adult health status: Educational attainment and healthy behaviors. Health Psychology, 26(1), 121-125.

Hanson, J. L., Chandra, A., Wolfe, B. L., \& Pollak, S. D. (2011). Association between income and the hippocampus. PLoS One, 6(5), e18712.

Hardy, L. (2006). Children at risk. American School Board Journal, 193(12), 17-21.

Harter, S. (2012). The construction of the self. New York, NY: The Guildford Press.

Hastings, P. D., Shirtcliff, E. A., Klimes-Dougan, B., Allison, A. L., Derose, L., Kendziora, K. T., \& Zahn-Waxler, C. (2011). Allostasis and the development of internalizing and externalizing problems: Changing relations with physiological systems across adolescence. Development and Psychopathology, 23(4), $1149-1165$

Hertzaman, C., \& Boyce, T. (2010). How experiences gets under the skin to create gradients in developmental health. Annual Review of Public Health, 31, 329-347.

Hildyard, K. L., \& Wolfe, D. A. (2002). Child neglect: Developmental issues and outcomes. Child Abuse and Neglect, 26(6), 679-695.

James, S. A. (1994). John Henryism and the health of African-Americans. Culture, Medicine and Psychiatry, 18(2), 163-182.

Johnson, W., \& Krueger, R. F. (2005). Genetic effects on physical health: Lower at higher income levels. Behavior Genetics, 35(5), 579-590.

Jonassaint, C. R., Siegler, I. C., Barefoot, J. C., Edwards, C. L., \& Williams, R. B. (2011). Low life course socioeconomic status (SES) is associated with negative NEO PI-R personality patterns. International Journal of Behavioral Medicine, 18(1), $13-21$.

Kerrigan, D., Witt, S., Glass, B., Chung, S. E., \& Ellen, J. (2006). Perceived neighborhood social cohesion and condom use among adolescents vulnerable to HIV/STI. AIDS and Behavior, 10(6), 723-729.

Kim-Spoon, J., Deater-Deckard, K., Holmes, C., Lee, J., Chiu, P., \& King-Casas, B. (2016). Behavioral and neural inhibitory control moderates the effects of reward sensitivity on adolescent substance use. Neuropsychologia, 91, 318-326.

King, A., Wardecker, B. M., \& Edelstein, R. S. (2015). Personal mastery buffers the effects of childhood sexual abuse on women's health and family functioning. Journal of Family Violence, 30(7), 887-897.

Kipke, M. D., Iverson, E., Moore, D., Booker, C., Ruelas, V., Peters, A. L., \& Kaufman, F. (2007). Food and park environments: Neighborhood-level risks for childhood obesity in East Los Angeles. Journal of Adolescent Health, 40(4), 325-333.

Kishiyama, M. M., Boyce, W. T., Jimenez, A. M., Perry, L. M., \& Knight, R. T. (2009). Socioeconomic disparities affect prefrontal function in children. Journal of Cognitive Neuroscience, 21(6), 1106-1115.

Knudsen, E. I. (2004). Sensitive periods in the development of the brain and behavior. Journal of Cognitive Neuroscience, 16(8), $1412-1425$.

Kogan, S. M., Brody, G. H., Chen, Y. F., Grange, C. M., Slater, L. M., \& DiClemente, R. J. (2010). Risk and protective factors for unprotected intercourse among rural African American young adults. Public Health Reports, 125, 709-717.

Kogan, S. M., Cho, J., Barnum, S. C., \& Brown, G. L. (2015). Correlates of concurrent sexual partnerships among young, rural African American men. Public Health Reports, 130(4), 392-399.

Konrad, K., Firk, C., \& Uhlhaas, P. J. (2013). Brain development during adolescence. Deutsches àarzteblatt International, $110(25), 425-431$.

Konttinen, H., Männistö, S., Sarlio-Lähteenkorva, S., Silventoinen, K., \& Haukkala, A. (2010). Emotional eating, depressive symptoms and self-reported food consumption. A populationbased study. Appetite, 54(3), 473-479.

Lee, T. L. (2015). The influence of life transition patterns on the continuity and change in psychopathology from adolescence to young adulthood and their precursors. Unpublished doctoral dissertation. Athens, GA: The University of Georgia.

Loktionov, A., Scollen, S., McKeown, N., \& Bingham, S. A. (2000). Gene-nutrient interactions: dietary behaviour associated with high coronary heart disease risk particularly affects serum LDL cholesterol in apolipoprotein E $\varepsilon 4$-carrying free-living individuals. British Journal of Nutrition, 84(06), $885-890$.

Loman, M. M., \& Gunnar, M. R. (2010). Early experience and the development of stress reactivity and regulation in children. Neuroscience and Biobehavioral Reviews, 34(6), 867-876.

Lopez, B., Schwartz, S. J., Prado, G., Campo, A. E., \& Pantin, H. (2008). Adolescent neurological development and its implications for adolescent substance use prevention. The Journal of Primary Prevention, 29(1), 5-35.

Lovallo, W. R. (2013). Early life adversity reduces stress reactivity and enhances impulsive behavior: Implications for health behaviors. International Journal of Psychophysiology, 90(1), $8-16$.

Lund, L. K., Vik, T., Lydersen, S., Løhaugen, G. C., Skranes, J., Brubakk, A. M., \& Indredavik, M. S. (2012). Mental health, quality of life and social relations in young adults born with low birth weight. Health and Quality of Life Outcomes, 10, 146.

Lupien, S. J., McEwen, B. S., Gunnar, M. R., \& Heim, C. (2009). Effects of stress throughout the lifespan on the brain, behaviour and cognition. Nature Reviews Neuroscience, 10(6), 434-445.

Luthar, S. S., Cicchetti, D., \& Becker, B. (2000). The construct of resilience: A critical evaluation and guidelines for future work. Child Development, 71(3), 543-562.

Macht, M. (2008). How emotions affect eating: A five-way model. Appetite, 50(1), 1-11. 
Macht, M., Haupt, C., \& Ellgring, H. (2005). The perceived function of eating is changed during examination stress: A field study. Eating Behaviors, 6(2), 109-112.

Matthews, K. A., \& Gallo, L. C. (2011). Psychological perspectives on pathways linking socioeconomic status and physical health. Annual Review of Psychology, 62, 501-530.

McCutcheon, V. V., Sartor, C. E., Pommer, N. E., Bucholz, K. K., Nelson, E. C., Madden, P. A., \& Heath, A. C. (2010). Age at trauma exposure and PTSD risk in young adult women. Journal of Traumatic Stress, 23(6), 811-814.

McEwen, B. S. (1998). Stress, adaptation, and disease: Allostasis and allostatic load. Annals of the New York Academy of Sciences, 840(1), 33-44.

McEwen, B. S. (2012). Brain on stress: How the social environment gets under the skin. Proceedings of the National Academy of Sciences, 109(Supplement 2), 17180-17185.

McEwen, B. S., \& Gianaros, P. J. (2010). Central role of the brain in stress and adaptation: Links to socioeconomic status, health, and disease. Annals of the New York Academy of Sciences, 1186(1), 190-222.

Meaney, M. J. (2010). Epigenetics and the biological definition of gene $\times$ environment interactions. Child Development, 81(1), 41-79.

Melby, J. N., Conger, R. D., Fang, S. A., Wickrama, K. A. S., \& Conger, K. J. (2008). Adolescent family experiences and educational attainment during early adulthood. Developmental Psychology, 44(6), 1519-1536.

Meyer, I. H. (1995). Minority stress and mental health in gay men. Journal of Health and Social Behavior, 36, 38-56.

Miller, G. E., \& Chen, E. (2010). Harsh family climate in early life presages the emergence of a proinflammatory phenotype in adolescence. Psychological Science, 21, 848-856.

Miller, G. E., Chen, E., \& Parker, K. J. (2011). Psychological stress in childhood and susceptibility to the chronic diseases of aging: Moving toward a model of behavioral and biological mechanisms. Psychological Bulletin, 137(6), 959-997.

Miller, G. E., \& Cole, S. W. (2012). Clustering of depression and inflammation in adolescents previously exposed to childhood adversity. Biological Psychiatry, 72(1), 34-40.

Moffitt, T. E. (1993). Adolescence-limited and life-course-persistent antisocial behavior: A developmental taxonomy. Psychological Review, 100(4), 674-701.

Moffitt, T. E., Arseneault, L., Belsky, D., Dickson, N., Hancox, R. J., Harrington, H., \& Sears, M. R., et al. (2011). A gradient of childhood self-control predicts health, wealth, and public safety. Proceedings of the National Academy of Sciences, 108(7), 2693-2698.

Nam, Y., \& Huang, J. (2009). Equal opportunity for all? Parental economic resources and children's educational attainment. Children and Youth Services Review, 31(6), 625-634.

Noble, K. G., Houston, S. M., Kan, E., \& Sowell, E. R. (2012). Neural correlates of socioeconomic status in the developing human brain. Developmental Science, 15(4), 516-527.

Noh, S., Beiser, M., Kaspar, V., Hou, F., \& Rummens, J. (1999). Perceived racial discrimination, depression, and coping: A study of Southeast Asian refugees in Canada. Journal of Health and Social Behavior, 40, 193-207.

Noh, S., \& Kaspar, V. (2003). Perceived discrimination and depression: Moderating effects of coping, acculturation, and ethnic support. American Journal of Public Health, 93(2), 232-238.

Non, A. L., Hollister, B. M., Humphreys, K. L., Childebayeva, A., Esteves, K., Zeanah, C. H., \& Drury, S. S., et al. (2016). DNA methylation at stress-related genes is associated with exposure to early life institutionalization. American Journal of Physical Anthropology. doi:10.1002/ajpa.23010.
Nurius, P. S., Prince, D. M., \& Rocha, A. (2015). Cumulative disadvantage and youth well-being: A multi-domain examination with life course implications. Child and Adolescent Social Work Journal, 32(6), 567-576.

O'Rand, A. M., \& Hamil-Luker, J. (2005). Processes of cumulative adversity: Childhood disadvantage and increased risk of heart attack across the life course. The Journals of Gerontology Series B: Psychological Sciences and Social Sciences, 60(Special Issue 2), S117-S124.

Oshri, A., Carlson, M. W., Kwon, J. A., Zeichner, A., \& Wickrama, K. A. S. (2016). Developmental growth trajectories of selfesteem in adolescence: Associations with child neglect and drug use and abuse in young adulthood. Journal of Youth and Adolescence. doi:10.1007/s10964-016-0483-5.

Packard, C. J., Bezlyak, V., McLean, J. S., Batty, G. D., Ford, I., Burns, H., \& Millar, K. (2011). Early life socioeconomic adversity is associated in adult life with chronic inflammation, carotid atherosclerosis, poorer lung function and decreased cognitive performance: a cross-sectional, population-based study. $B M C$ Public Health, 11(1), 42.

Pearlin, L. I., Menaghan, E. G., Lieberman, M. A., \& Mullan, J. T. (1981). The stress process. Journal of Health and Social Behavior, 22, 337-356.

Pearlin, L. I., Schieman, S., Fazio, E. M., \& Meersman, S. C. (2005). Stress, health, and the life course: Some conceptual perspectives. Journal of Health and Social Behavior, 46(2), 205-219.

Prawitz, A. D., Kalkowski, J. C., \& Cohart, J. (2013). Responses to economic pressure by low-income families: Financial distress and hopefulness. Journal of Family and Economic Issues, 34(1), 29-40.

Raposa, E. B., Bower, J. E., Hammen, C. L., Najman, J. M., \& Brennan, P. A. (2014). A developmental pathway from early life stress to inflammation the role of negative health behaviors. Psychological Science, 25(6), 1268-1274.

Raposa, E. B., Laws, H. B., \& Ansell, E. B. (2015). Prosocial behavior mitigates the negative effects of stress in everyday life. Clinical Psychological Science, 4, 691-698.

Repetti, R. L., Robles, T. F., \& Reynolds, B. (2011). Allostatic processes in the family. Development and Psychopathology, 23(3), 921-938.

Repetti, R. L., Taylor, S. E., \& Seeman, T. E. (2002). Risky families: Family social environments and the mental and physical health of offspring. Psychological Bulletin, 128(2), 330-366.

Ribeiro, L. A., Zachrisson, H. D., Schjolberg, S., Aase, H., RohrerBaumgartner, N., \& Magnus, P. (2011). Attention problems and language development in preterm low-birth-weight children: Cross-lagged relations from 18 to 36 months. BMC Pediatrics, 11(1), 59-70.

Ross, C. E., \& Mirowsky, J. (2009). Neighborhood disorder, subjective alienation, and distress. Journal of Health and Social Behavior, 50(1), 49-64.

Ross, C. E., \& Mirowsky, J. (2010). Why education is the key to socioeconomic differentials in health. In C. E. Bird, P. Conrad, A. M. Fremont \& S. Timmermans (Eds.), Handbook of medical sociology (6th edn., pp. 33-51). Nashville, TN: Vanderbilt University Press.

Ross, C. E., Reynolds, J. R., \& Geis, K. J. (2000). The contingent meaning of neighborhood stability for residents' psychological well-being. American Sociological Review, 65, 581-597.

Rutter, M. (1999). Resilience concepts and findings: Implications for family therapy. Journal of Family Therapy, 21(2), 119-144.

Ruttle, P. L., Maslowsky, J., Armstrong, J. M., Burk, L. R., \& Essex, M. J. (2015). Longitudinal associations between diurnal cortisol slope and alcohol use across adolescence: A seven-year prospective study. Psychoneuroendocrinology, 56, 23-28. 
Sapolsky, R. M. (2000). Stress hormones: Good and bad. Neurobiology of Disease, 7(5), 540-542.

Schreier, H., \& Chen, E. (2013). Socioeconomic status and the health of youth: A multilevel, multidomain approach to conceptualizing pathways. Psychological Bulletin, 139(3), 606-654.

Seeman, T., Epel, E., Gruenewald, T., Karlamangla, A., \& McEwen, B. S. (2010). Socio-economic differentials in peripheral biology: Cumulative allostatic load. Annals of the New York Academy of Sciences, 1186(1), 223-239.

Shanahan, M. J., \& Boardman, J. D. (2009). Gene-environment interplay across the life course: Overview and problematics at a new frontier. In J. Z. Giele JZ \& G. H. Elder Jr. (Eds.), Methods of life course research: Qualitative and quantitative approaches. Thousand Oaks, CA: Sage.

Shin, S. H., \& Miller, D. P. (2012). A longitudinal examination of childhood maltreatment and adolescent obesity: results from the National Longitudinal Study of Adolescent Health (AddHealth) Study. Child Abuse and Neglect, 36(2), 84-94.

Shonkoff, J. P., Boyce, W. T., \& McEwen, B. S. (2009). Neuroscience, molecular biology, and the childhood roots of health disparities: Building a new framework for health promotion and disease prevention. JAMA: The Journal of the American Medical Association, 301(21), 2252-2259.

Shonkoff, J. P., Garner, A. S., Siegel, B. S., Dobbins, M. I., Earls, M. F., McGuinn, L., \& Wood, D. L., et al. (2012). The lifelong effects of early childhood adversity and toxic stress. Pediatrics, 129(1), e232-e246.

Simons, R. L., \& Lei, M. K. (2013). Enhanced susceptibility to context: A promising perspective on the interplay of genes and the social environment. In C. L. Gibson \& M. D. Krohn (Eds.), Handbook of life-course criminology: Emerging trends and directions for future research (pp. 57-67). New York, NY: Springer.

Smith, J. R., Brooks-Gunn, J., \& Klebanov, P. (1997). The consequences of living in poverty for young children's cognitive and verbal ability and early school achievement. In G. J. Duncan \& J. Brooks-Gunn (Eds.), Consequences of growing up poor (pp. 132-189). New York, NY: Russell Sage.

Solar, O., \& Irwin, A. (2010). A conceptual framework for action on the social determinants of health. In: Commission on social determinants of health discussion paper 2 (Policy and Practice).

Squeglia, L. M., Jacobus, J., \& Tapert, S. F. (2009). The influence of substance use on adolescent brain development. Clinical EEG and Neuroscience, 40(1), 31-38.

Stack, D. M., Serbin, L. A., Mantis, I., \& Kingdon, D. (2015). Breaking the cycle of adversity in vulnerable children and families: A thirty-five year study of at-risk lower income families. International Journal for Family Research and Policy, 1(1), 31-56.

Steinberg, L. (2001). We know some things: Parent-adolescent relationships in retrospect and prospect. Journal of Research on Adolescence, 11(1), 1-19.

Steinberg, L. (2004). Risk taking in adolescence: What changes, and why? Annals of the New York Academy of Sciences, 1021(1), 51-58.

Steinberg, L. (2008). A social neuroscience perspective on adolescent risk-taking. Developmental Review, 28(1), 78-106.

Steptoe, A., O’Donnell, K., Marmot, M., \& Wardle, J. (2008). Positive affect and psychosocial processes related to health. British Journal of Psychology, 99(2), 211-227.

Steptoe, A., Wardle, J., \& Marmot, M. (2005). Positive affect and health-related neuroendocrine, cardiovascular, and inflammatory processes. Proceedings of the National Academy of Sciences of the United States of America, 102(18), 6508-6512.

Steyn, N. P., Mann, J., Bennett, P. H., Temple, N., Zimmet, P., Tuomilehto, J., \& Louheranta, A. (2004). Diet, nutrition and the prevention of type 2 diabetes. Public Health Nutrition, 7, 147-165.

Stringhini, S., Batty, G. D., Bovet, P., Shipley, M. J., Marmot, M. G., Kumari, M., \& Kivimäki, M. (2013). Association of lifecourse socioeconomic status with chronic inflammation and type 2 diabetes risk: The Whitehall II prospective cohort study. PLoS Medicine, 10(7), e1001479.

Su, S., Wang, X., Pollock, J. S., Treiber, F. A., Xu, X., Snieder, H., \& Harshfield, G. A., et al. (2015). Adverse childhood experiences and blood pressure trajectories from childhood to young adulthood the Georgia Stress and Heart Study. Circulation, 131(19), 1674-1681.

Telzer, E. H., Fuligni, A. J., Lieberman, M. D., \& Galván, A. (2013). Ventral striatum activation to prosocial rewards predicts longitudinal declines in adolescent risk taking. Developmental Cognitive Neuroscience, 3, 45-52.

Tomporowski, P. D., Lambourne, K., \& Okumura, M. S. (2011). Physical activity interventions and children's mental function: An introduction and overview. Preventive Medicine, 52, S3-S9.

Umberson, D., Liu, H., \& Reczek, C. (2008). Stress and health behaviour over the life course. Advances in Life Course Research, 13, $19-44$.

Waldman, I. D. (2007). Gene-environment interactions reexamined: Does mother's marital stability interact with the dopamine receptor D2 gene in the etiology of childhood attention-deficit/ hyperactivity disorder? Development and Psychopathology, 19(4), 1117-1128.

Walum, H., Westberg, L., Henningsson, S., Neiderhiser, J. M., Reiss, D., Igl, W., \& Lichtenstein, P. (2008). Genetic variation in the vasopressin receptor 1a gene (AVPR1A) associates with pairbonding behavior in humans. Proceedings of the National Academy of Sciences, 105(37), 14153-14156.

Wargelius, H. L., Malmberg, K., Larsson, J. O., \& Oreland, L. (2012). Associations of MAOA-VNTR or 5HTT-LPR alleles with attention-deficit hyperactivity disorder symptoms are moderated by platelet monoamine oxidase B activity. Psychiatric Genetics, 22(1), 42-45.

Wen, M., \& Maloney, T. N. (2011). Latino residential isolation and the risk of obesity in Utah: The role of neighborhood socioeconomic, built-environmental, and subcultural context. Journal of Immigrant and Minority Health, 13(6), 1134-1141.

Wheaton, B., \& Clarke, P. (2003). Space meets time: Integrating temporal and contextual influences on mental health in early adulthood. American Sociological Review, 68, 680-706.

Whitbeck, L. B., Simons, R. L., Conger, R. D., Lorenz, F. O., Huck, S., \& Elder, G. H. Jr. (1991). Family economic hardship, parental support, and adolescent self-esteem. Social Psychology Quarterly, 54, 353-363.

Wickrama, K. A. S., \& Bryant, C. M. (2003). Community context of social resources and adolescent mental health. Journal of Marriage and Family, 65(4), 850-866.

Wickrama, K. A. S., Conger, R. D., Wallace, L. E., \& Elder, G. H. Jr. (1999). The intergenerational transmission of health-risk behaviors: Adolescent lifestyles and gender moderating effects. Journal of Health and Social Behavior, 40, 258-272.

Wickrama, K. A. S., Lee, T. K., \& O’Neal, C. W. (2015a). Stressful life experiences in adolescence and cardiometabolic risk factors in young adulthood. Journal of Adolescent Health, 56(4), 456-463.

Wickrama, K. A. S., Lee, T. K., \& O’Neal, C. W. (2017). Genetic moderation of multiple pathways linking early cumulative socioeconomic adversity and young adults' cardio-metabolic disease risk. Development and Psychopathology.

Wickrama, K. A. S., Lee, T. K., O’Neal, C. W., \& Kwon, J. A. (2015b). Stress and resource pathways connecting early 
socioeconomic adversity to young adults' physical health risk. Journal of Youth and Adolescence, 44(5), 1109-1124.

Wickrama, K. A. S., Merten, M. J., \& Elder, G. H. Jr. (2005). Community influence on precocious transitions to adulthood: Racial differences and mental health consequences. Journal of Community Psychology, 33(6), 639-653.

Wickrama, K. A. S., \& O'Neal, C. W. (2015). The socioeconomic pathways leading to romantic relationship outcomes: A genetically informed early life course investigation. Journal of Research on Adolescence, 26, 492-508.

Wickrama, K. A. S., O'Neal, C. W., \& Lee, T. K. (2013). Early community context, genes, and youth body mass index trajectories: An investigation of gene-community interplay over early life course. Journal of Adolescent Health, 53(3), 328-334.

Wickrama, K. A. S., O’Neal, C. W., \& Lee, T. K. (2016a). Cumulative socioeconomic adversity, developmental pathways, and mental health risks during the early life course. Emerging Adulthood, 4(6), 378-390.

Wickrama, K. A. S., O’Neal, C. W., \& Lee, T. K. (2016b). The health impact of upward mobility: Does socioeconomic attainment make youth more vulnerable to stressful circumstances? Journal of Youth and Adolescence, 45(2), 271-285.

Wickrama, K. A. S., O’Neal, C. W., Lee, T. K., \& Wickrama, T. (2015). Early socioeconomic adversity, youth positive development, and young adults' cardio-metabolic disease risk. Health Psychology, 34(9), 905-914.

Wickrama, T., Wickrama, K. A. S., \& Baltimore, D. L. (2010). Adolescent precocious development and young adult health outcomes. Advances in Life Course Research, 15(4), 121-131.

Willson, A. E., Shuey, K. M., \& Elder, G. H. Jr. (2007). Cumulative advantage processes as mechanisms of inequality in life course health. American Journal of Sociology, 112(6), 1886-1924.

Zhang, L. F. (2003). Does the big five predict learning approaches? Personality and Individual Differences, 34(8), 1431-1446.

Zilioli, S., Slatcher, R. B., Chi, P., Li, X., Zhao, J., \& Zhao, G. (2016). Childhood adversity, self-esteem, and diurnal cortisol profiles across the life span. Psychological Science. doi: $10.1177 / 0956797616658287$. 